TP Periodica Polytechnica Civil Engineering

\author{
62(1), pp. 226-231, 2018 \\ https://doi.org/10.3311/PPci.11184 \\ Creative Commons Attribution (i)
}

RESEARCH ARTICLE

\section{Experimental and Analytical Analysis of Creep of Steel Fibre Reinforced Concrete}

\author{
Darko Nakov ${ }^{1 *}$, Goran Markovski ${ }^{1}$, Toni Arangjelovski ${ }^{1}$, Peter Mark ${ }^{2}$
}

Received 23 June 2017; Revised 15 August 2017; Accepted 22 August 2017

\begin{abstract}
To find out the influence of different fibre dosages on the creep of SFRC (Steel fibre reinforced concrete), an experiment was carried out at the Faculty of Civil Engineering-Skopje. The experiment involved 9 specimens manufactured with concrete class C30/37 and reinforced with different amount of fibres (0, 30 and $60 \mathrm{~kg} / \mathrm{m} 3)$. According to the experimental results obtained up to the age of 400 days, the addition of steel fibres had an influence on the creep strains (a decrease of up to $12 \%$ ). Based on the experimental results, analytical analyses of creep were performed by use of the B3 model and fib Model Code 2010. The analyses were prolonged up to the estimated age of service life of structures of 100 years. According to the $B 3$ model, at the age of 100 years, the decrease of the creep coefficient is $11.1 \%$ in the case of the SFRC type C30/37 FL $1.5 / 1.5$, while in the case of C30/37 FL 2.5/2.0, it is $17.8 \%$, when compared to C30/37.
\end{abstract}

\section{Keywords}

creep, concrete, SFRC, experiment, 33 model, fib Model Code 2010

\footnotetext{
${ }^{1}$ Chair for Concrete and Timber Structures,

Faculty of Civil Engineering,

"Ss.Cyril and Methodius" University,

Blvd. Partizanski odredi 24, 1000 Skopje, Republic of Macedonia

${ }^{2}$ Institute of Concrete Structures,

Faculty of Civil and Environmental Engineering, Ruhr-University Bochum,

Universitätsstraße 150, 44801 Bochum, Germany

*Corresponding author, e-mail: nakov@gf.ukim.edu.mk
}

\section{Introduction}

Steel fibre reinforced concrete is a material that still struggles for its place on the market of construction materials. Although many research studies and experiments have been performed, there are many properties [1], [2], [3] that are under research at the moment. One of the most complex properties is the one that includes the time as a parameter in the analysis.

This paper presents the results from the experimental and analytical analysis of creep of SFRC.

Up to now, there have been some experimental results from testing of creep of SFRC, but mainly leading to different conclusions.

The Report on FRC published by ACI [4] shows that, according to the limited test data on creep of SFRC, if fibres are used to the amount of less than $1 \%$ of the volume, there is no significant improvement in creep strain. Balaguru and Ramakrishnan found that $0.5 \%$ of steel fibres lead to slightly increased creep strains [5]. Houde et al. found that $1.0 \%$ of steel fibres increase the creep strain by $20-40 \%$. On the other hand, Chern and Chang found that steel fibres reduce the creep strain [6]. Swamy and Theodorakopoulos have reported that inclusion of $1 \%$ fibres results in improved creep properties of concrete under flexure [7]. Hannant has reported that steel fibres have no significant effects on creep properties of concrete [8].

Mangat and Azari proposed a theoretical expression to predict creep of SFRC, based on the knowledge of creep of ordinary concrete, coefficient of friction, fibre volume and aspect ratio of the fibres [9]:

$$
\varepsilon_{f c}=\varepsilon_{o c}\left(1-1.96 \mu v_{f} \frac{l}{d}\right)
$$

where:

$\varepsilon_{f c}-$ is the creep strain of SFRC;

$\varepsilon_{o c}-$ is the creep strain of ordinary concrete;

$\mu-$ is the coefficient of friction;

$v_{f}-$ is the fibre volume;

$l / d-$ is the aspect ratio of the fibres.

According to this expression, the decreasing of creep of SFRC, compared to ordinary concrete, ranges from 0 to $30 \%$ [9]. 
Knowing of the time-dependent properties of any type of concrete is very important if we want to use it as a structural material. Exact prediction of creep strains, as a material properties problem, is a prerequisite for determination of the timedependent structural response.

\section{Creep of concrete}

\subsection{General}

Generally, the total concrete strain $\varepsilon_{c}(t)$ at any time, in an uncracked, uniaxially-loaded concrete element, at time $t_{0}\left(t>t_{0}\right)$, with constant stress $\sigma_{c}\left(t_{0}\right)$, can be presented as a sum of the separate strains [10]:

$$
\varepsilon_{c}(t)=\varepsilon_{c i}\left(t_{0}\right)+\varepsilon_{c c}(t)+\varepsilon_{c s}(t)+\varepsilon_{c T}(t)
$$

If temperature is kept constant [10]:

where:

$$
\varepsilon_{c}(t)=\varepsilon_{c i}\left(t_{0}\right)+\varepsilon_{c c}(t)+\varepsilon_{c s}(t)
$$

$\varepsilon_{c}(t)$ - is the total strain in concrete at time $(t)$;

$\varepsilon_{c i}\left(t_{0}\right)$ - is the instantaneous strain in concrete at loading at time $\left(t_{0}\right)$;

$\varepsilon_{c c}(t)$ - is the strain from concrete creep at time $(t)$;

$\varepsilon_{c s}(t)$ - is the strain from shrinkage at time $(t)$;

$\varepsilon_{c T}(t)$ - is the strain from temperature or thermal strain at time $(t)$.

Equation 1 can also be written in the following form [10]:

$$
\varepsilon_{c}(t)=\varepsilon_{c \sigma}(t)+\varepsilon_{c n}(t)
$$

where:

$\varepsilon_{c \sigma}(t)-$ is the stress-dependent strain in concrete at time $(t)$ : $\varepsilon_{c \sigma}(t)=\varepsilon_{c i}\left(t_{0}\right)+\varepsilon_{c c}(t)$

$\varepsilon_{c n}(t)$ - is the stress-independent strain in concrete at time $(t)$ : $\varepsilon_{c n}(t)=\varepsilon_{c s}(t)+\varepsilon_{c T}(t)[10]$.

Although not strictly correct, it is usually assumed that all four components are independent and can be calculated separately and combined to obtain the total strain [11].

Immediately after concrete setting, or at the end of moist curing $\left(t=t_{d}\right)$, shrinkage strains begin to develop and continue to increase at a decreasing rate. At the moment of application of stress, or at the moment of loading $\left(t=t_{0}\right)$, a sudden rise in strain occurs that is called instantaneous or elastic strain. Under the effect of such applied sustained stress, the strain increases with time due to the creep of concrete.

\subsection{Instantenous (elastic) strain}

The strain, which occurs during the application of the stress, is reffered to as elastic, initial or instantenous strain. For service loads, it is usually assumed that the stress in concrete is proportional to strain. Therefore, the instantenous strain can be expressed as follows [11]:

$$
\varepsilon_{c i}\left(t_{0}\right)=\frac{\sigma_{c}\left(t_{0}\right)}{E_{c}\left(t_{0}\right)}
$$

Where $\sigma_{c}\left(t_{0}\right)$ is the applied concrete stress at time $t_{0}$, while $E_{c}\left(t_{0}\right)$ is the secant modulus of elasticity at the same age when the stress was applied.

\subsection{Creep}

When concrete is subjected to a sustained stress, instantaneous strain appears and gradually increases with time due to the creep of concrete. In the period immediately after the initial loading, creep develops rapidly, where at the rate of increase is slowed down with time. It is thought that about $50 \%$ of the final creep develops in the first 2-3 months and about $90 \%$ develops after 2-3 years. Due to the fact that creep and shrinkage are phenomena that never occur separately, creep is usually calculated as the difference between the total time-dependent strain of a loaded specimen and the shrinkage of the same, but unloaded specimen.

When the sustained concrete stress is less than $0.5 \mathrm{fc}$, the creep is almost proportional to the stress and it is called a linear creep. If the stress levels are higher, which is almost never the case in service, than the creep increases at a faster rate due to the increased micro-cracking and becomes non-linear with respect to stress.

Generally, the creep is composed from a basic creep, which is the time-dependent strain in a loaded specimen in hygral equilibrium with the ambient medium (there is no drying), and a drying creep, which is the additional creep that occurs in a drying specimen.

Creep is caused by many complex mechanisms that are still not fully understood. It includes many micro-mechanisms originating from the hardened cement paste that consists of a solid cement gel containing many capillary pores and is made of colloidal sheets of calcium silicate hydrates separated by spaces containing absorbed water. The difference in the amount of capillary pores between normal and high-strength concrete actually causes bigger creep strains in normal concrete. Neville et al. identified the following mechanisms of creep:

- Sliding of the colloidal sheets in the cement gel between the layers of absorbed water - viscous flow;

- Expulsion and decomposition of the interlayer water within the cement gel - seepage;

- Elastic deformation of the aggregate and the gel crystals as viscous flow and seepage occur within the cement gel delayed elasticity;

- Local fracture within the cement gel involving breakdown (and formation) of physical bonds - microcracking;

- Mechanical deformation theory, and

- Plastic flow.

The magnitude and rate of development of creep depend on many factors. Creep increases when:

- the concrete strength decreases;

- the content of the aggregate decreases;

- less stiffer aggregates are used; 
- the water/cement ratio increases;

- the relative humidity decreases;

- there is an increase of temperature that accelerates drying;

- the intensity of the sustained stress is increased;

- the duration of the stress is longer and

- the age of the concrete is smaller at the first application of the stress.

Creep is usually measured and introduced in the design of concrete structures in terms of creep coefficient $\varphi\left(t, t_{0}\right)$. Creep coefficient at any time $t$ is the ratio between the creep strain and the instantaneous strain [11]:

$$
\phi\left(t, t_{0}\right)=\frac{\varepsilon_{c c}\left(t, t_{0}\right)}{\varepsilon_{c i}\left(t_{0}\right)}
$$

Therefore, the creep strain at time $\mathrm{t}$ caused by a constant sustained stress $\sigma_{c}\left(t_{0}\right)$ first applied at age $t_{0}$ is [11]:

$$
\varepsilon_{c c}\left(t, t_{0}\right)=\phi\left(t, t_{0}\right) \varepsilon_{c i}\left(t_{0}\right)=\phi\left(t, t_{0}\right) \frac{\sigma_{c}\left(t_{0}\right)}{E_{c}\left(t_{0}\right)}
$$

In this way, if we know the creep coefficient, we can calculate the creep strain from any constant sustained stress at any time. It is assumed that, as time approaches infinity, the creep coefficient reaches a final value that usually ranges from 1.5-4.0.

If we want to express the stress induced strain, which means instantaneous plus creep strain, caused by a constant sustained stress [11]:

$$
\varepsilon_{c i}\left(t_{0}\right)+\varepsilon_{c c}\left(t, t_{0}\right)=\frac{\sigma_{c}\left(t_{0}\right)}{E_{c}\left(t_{0}\right)}\left[1+\phi\left(t, t_{0}\right)\right]
$$

\section{Experimental program}

To find out the influence of different fibre dosages on the creep of SFRC, an experiment was carried out at the "Ss. Cyril and Methodius" University, Faculty of Civil Engineering-Skopje, Republic of Macedonia, in the period October 2011 to December 2012 as a part of a large experimental programme. The experiment involved 9 specimens manufactured with concrete class C30/37. According to the type of material, they were divided into three series: Series A, ordinary concrete (C30/37); Series B, SFRC with $30 \mathrm{~kg} / \mathrm{m}^{3}$ (0.38\%) steel fibres (C30/37 FL1.5/1.5) and Series C, SFRC with $60 \mathrm{~kg} / \mathrm{m}^{3}$ $(0.76 \%)$ steel fibres (C30/37 FL2.5/2.0). The used steel fibres were hooked-end with a diameter of $1 \mathrm{~mm}$, length of $50 \mathrm{~mm}$ and tensile strength of $1100 \mathrm{~N} / \mathrm{mm}^{2}$. The fibres were produced of cold-drawn wire and their shape is presented in Fig. 1.

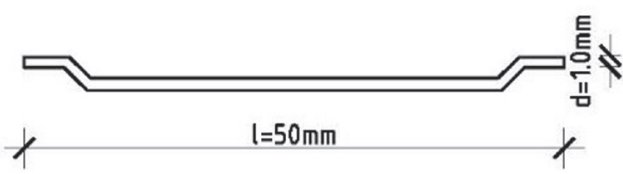

Fig. 1 Hooked-end steel fibre HE1/50

The mixture proportioning was the same for the three types of concrete. It is presented in Tab. 1
Table 1 Mixture proportions for the three concrete types

\begin{tabular}{lc}
\hline Mixture proportions & $\mathbf{( k g / \mathbf { m } ^ { 3 } )}$ \\
\hline Cement CEM II/A-M 42.5N & 410 \\
Water & 215 \\
Water/Cement ratio, w/c & 0.524 \\
Aggregate: & \\
0-4 mm (river sand), 50\% & 875 \\
4-8 mm (limestone), 20\% & 350 \\
8-16 mm (limestone), 30\% & 525 \\
Fibres: & \\
C30/37 & 0 \\
C30/37 FL 1.5/1.5 & 30 \\
C30/37 FL 2.5/2.0 & 60 \\
\hline
\end{tabular}

The control specimens were cured for 8 days in a chamber with constant temperature of $20 \pm 2^{\circ} \mathrm{C}$ and minimum of $95 \%$ humidity. Then they were transported to the Laboratory at the Faculty of Civil Engineering - Skopje, where they were kept under almost constant temperature of $19.8^{\circ} \mathrm{C}$ on the average and an average constant relative ambient humidity of $60.2 \%$, which was regulated with special humidifiers and dehumidifiers.

The creep strains were measured on three control prism specimens $(12 \times 12 \times 36 \mathrm{~cm})$ for each type of concrete. The strains were measured on four sides of each prism, meaning that, for each type of concrete, the results presented in the subsequent tables and figures represent mean values from 12 measurement points. The measurements were performed with mechanical deflection meter with a base of $250 \mathrm{~mm}$.

Compression creep was applied with creep frames (Fig. 2), while the stress level of the prism specimens was 7.5 MPa.

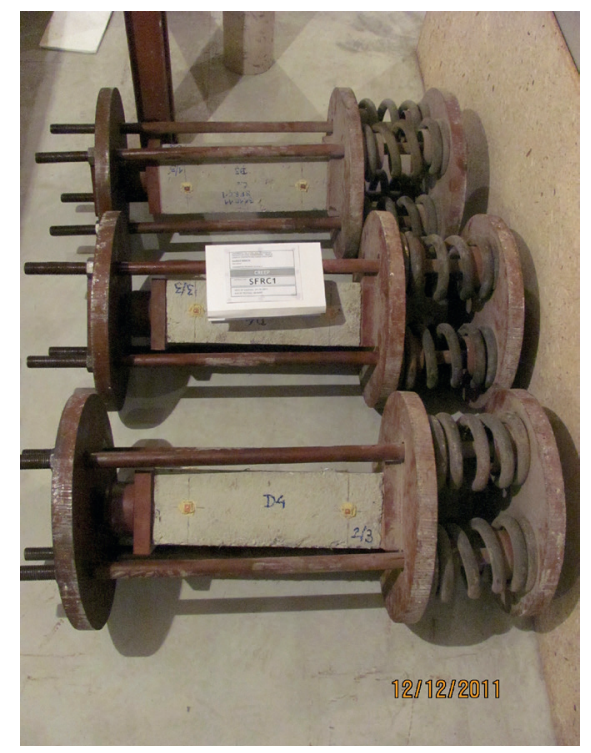

Fig. 2 Testing of concrete creep in creep frames

\section{Experimental results}

Tab. 2 and Fig. 3 show the results from the measurement of the creep strain and also from the measurement of the instantaneous, drying shrinkage and total strain. As it can be noticed from the table and the figure, the addition of fibres has an influence on the creep strain. 
Table 2 Time-dependent deformation properties for the three concrete types.

\begin{tabular}{lcccc}
\hline $\begin{array}{l}\text { Time-dependent } \\
\text { properties }\end{array}$ & $\begin{array}{c}\text { Age t } \\
\text { (days) }\end{array}$ & $\mathbf{C 3 0 / 3 7}$ & $\begin{array}{c}\mathbf{C 3 0} / \mathbf{3 7} \\
\mathbf{F L 1 . 5} / \mathbf{1 . 5}\end{array}$ & $\begin{array}{c}\mathbf{C 3 0} / \mathbf{3 7} \\
\mathbf{F L 2 . 5 / 2 . 0}\end{array}$ \\
\hline $\begin{array}{l}\text { Drying shrinkage } \varepsilon_{d s} \\
\text { [micro-strain] }\end{array}$ & 40 & 441.3 & 405.3 & 462.7 \\
\hline $\begin{array}{l}\text { Instantaneous strain } \varepsilon_{e} \\
{[\text { micro-strain] }}\end{array}$ & 400 & 808.0 & 805.0 & 794.9 \\
\hline $\begin{array}{l}\text { Creep strain } \varepsilon_{c c} \\
\text { [micro-strain] }\end{array}$ & 400 & 429.7 & 374.7 & 385.0 \\
\hline $\begin{array}{l}\text { Total strain } \\
\varepsilon=\varepsilon_{d s} 400+\varepsilon_{e}+\varepsilon_{c c} \\
{[\text { micro-strain] }}\end{array}$ & 400 & 1524.0 & 1433.7 & 1421.2 \\
\hline $\begin{array}{l}\text { Creep coefficient } \\
\phi\left(t, t_{0}\right)=\varepsilon_{c c} / \varepsilon_{e}\end{array}$ & 400 & 1.501 & 1.475 & 1.595 \\
\hline
\end{tabular}

In Fig. 4, only the creep strains are presented. The instantaneous strain, which is the reason for the appearance of the creep strain, is also presented. As it can be seen from the figures, the fibres have an influence on the creep strain. In the case of concrete types C30/37 FL 1.5/1.5 and C30/37 FL 2.5/2.0, the instantaneous strain decreased for 11.3 and $15.7 \%$, while the creep strain decreased for 12.8 and $10.4 \%$.

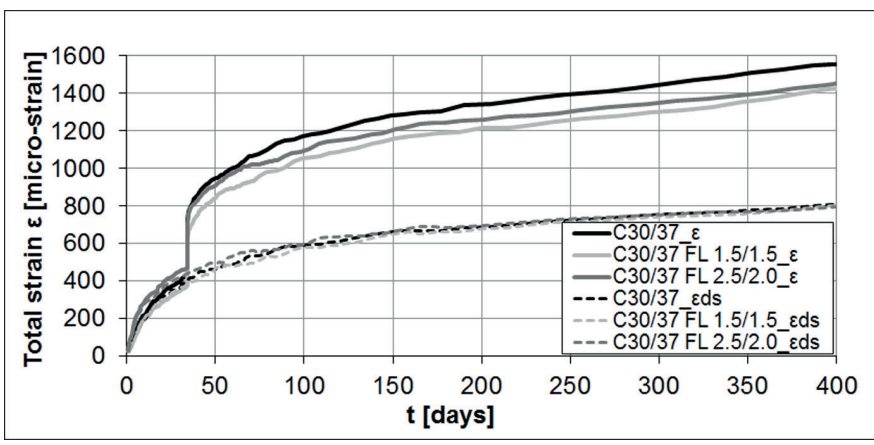

Fig. 3 Total strain for the three concrete types

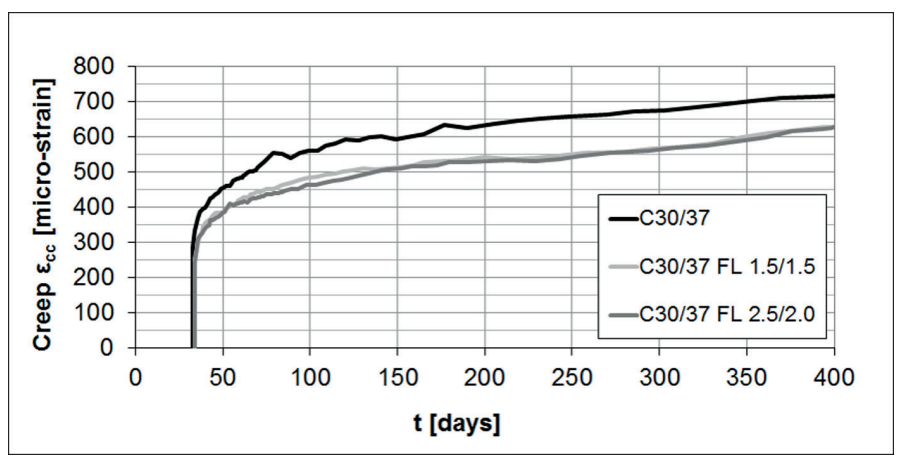

Fig. 4 Creep strain for the three concrete types

\section{Analytical analysis of creep}

Analytical analysis of the creep strain was performed by the B3 model [12] and fib Model Code 2010 [10]. At the beginning, the analysis was done only for the time period considered in this research, i.e., 400 days.

The fib Model Code 2010 overestimated the experimentally obtained creep coefficient at 400 days for $13 \%$, while the B3 model underestimated it for $9.5 \%$. Taking into consideration the coefficients of variation of each model, good agreement was found in all cases.
The B3 model offers the possibility of improvement of the model by its users by updating its predictions based on shorttime measurements [12]. On the basis of linear regression analysis, the following values for adjustment of the creep compliance in the B3 model were obtained: $p_{1}=1.143$ and $p_{2}=1.122$, which are valid only for the concrete type C30/37. For concrete type $\mathrm{C} 30 / 37$, the experimental and analytical results are presented in Fig. 5.

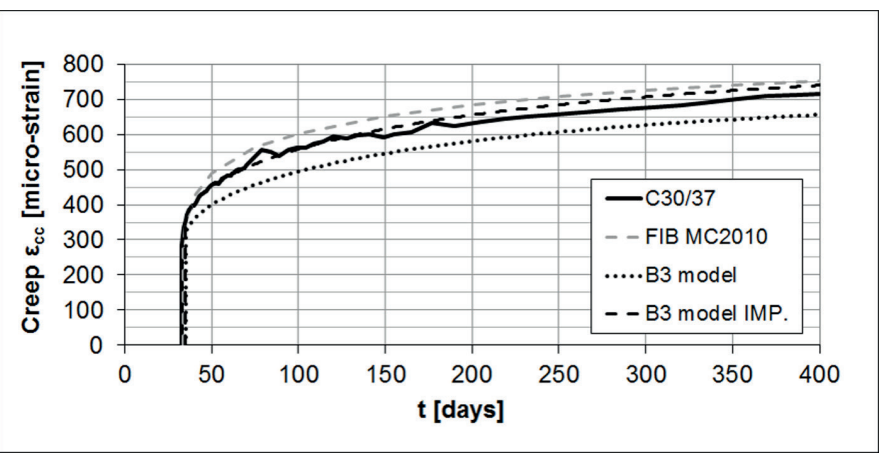

Fig. 5 Experimental and analytical results for creep of $\mathrm{C} 30 / 37$ up to the age of 400 days

With the original B3 model, the experimental results obtained for both types of steel fibre reinforced concrete, C30/37 FL 1.5/1.5 and C30/37 FL 2.5/2.0, exhibit a small difference in the final strain after 400 days. Therefore, for these types of concrete, modification of the flow compliance $q_{4}$ in the $\mathrm{B} 3$ model is proposed. The modification includes addition of the amount of fibers $G_{f}$ to the amount of aggregate $a$, multiplied by the ratio of the elasticity moduli of the fibers and the aggregate $E_{f} / E_{a}$.

where:

$$
q_{4}=20.3\left(\left(a+G_{f}\left(E_{f} / E_{a}\right)\right) / c\right)^{-0.7}
$$

$q_{4}$ - is the flow compliance;

$a-$ is the amount of aggregate;

$G_{f}-$ is the amount of fibers;

$E_{f} / E_{a}-$ is the ratio of the Elasticity moduli of the fibers and the aggregate;

$c-$ is the amount of cement.

With this modification, the analytically obtained final strain after 400 days was closer to the experimental one.

The results for the concrete type C30/37 FL 2.5/2.0 with 60 $\mathrm{kg} / \mathrm{m}^{3}$ are presented in Fig. 6 .

Based on the results obtained up to the age of 400 days, the analyses of the creep strain according to the previously mentioned models were prolonged up to the age of service life of structures of 100 years. These results are presented in Fig. 7 and Tab. 3 for concrete type C30/37 and in Fig. 8 and Tab. 4 for concrete type C30/37 FL 2.5/2.0. 


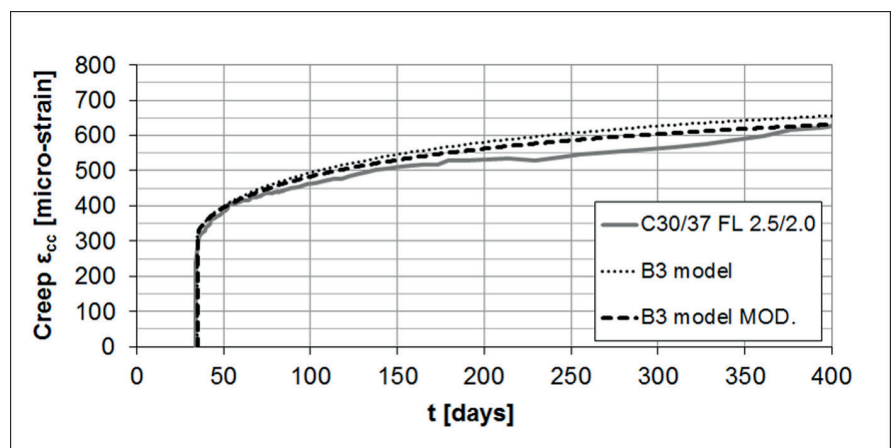

Fig. 6 Experimental and analytical results for creep of C30/37 FL 2.5/2.0 up to the age of 400 days

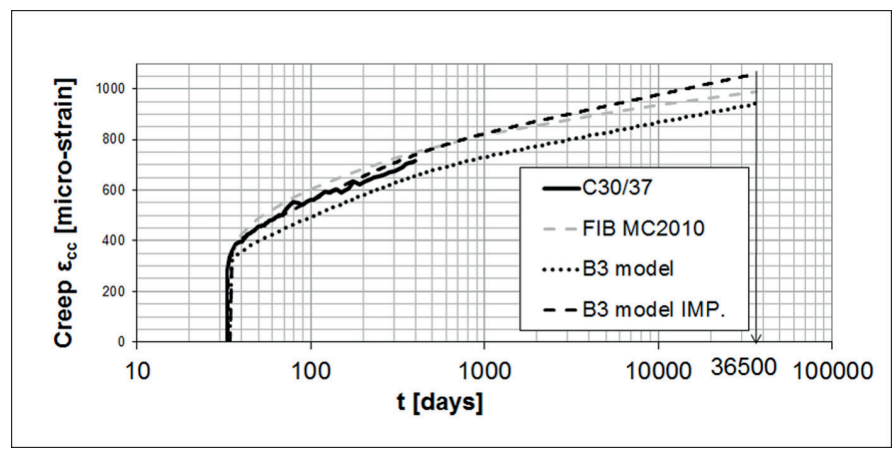

Fig. 7 Experimental and analytical results for creep of $\mathrm{C} 30 / 37$ up to the age of 100 years in logarithmic scale

Table 3 Creep coefficient for concrete type C30/37 up to the age of 100 years

\begin{tabular}{lcccc}
\hline \multirow{2}{*}{$\begin{array}{l}\text { Creep } \\
\text { coeff. }\end{array}$} & \multirow{2}{*}{$\begin{array}{c}\text { Age t } \\
\text { (year) }\end{array}$} & FIB MC 2010 & B3 model & B3 model imp. \\
\cline { 3 - 5 } & 2 & 1.869 & 1.544 & 1.867 \\
$\varphi\left(t, t_{0}\right)$ & 50 & 2.449 & 2.242 & 2.650 \\
& 100 & 2.548 & 2.384 & 2.810 \\
\hline
\end{tabular}

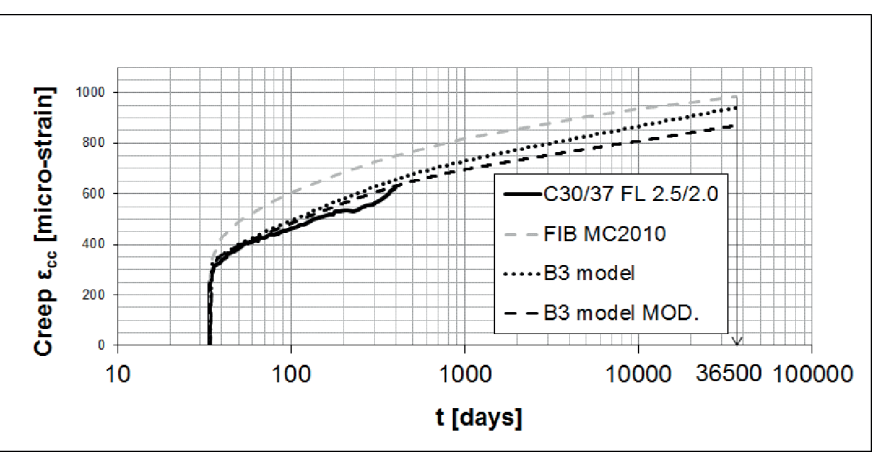

Fig. 8 Experimental and analytical results for creep of C30/37 FL 2.5/2.0 up to the age of 100 years in logarithmic scale

Table 4 Creep coefficient for concrete type C30/37 up to the age of 100 years

\begin{tabular}{lccccc}
\hline \multirow{2}{*}{$\begin{array}{l}\text { Creep } \\
\text { coefficient }\end{array}$} & $\begin{array}{c}\text { Age t } \\
\text { (year) }\end{array}$ & \multicolumn{2}{c}{$\begin{array}{c}\text { All concrete } \\
\text { types }\end{array}$} & $\begin{array}{c}\text { C30/37 FL } \\
\mathbf{1 . 5} / \mathbf{1 . 5}\end{array}$ & $\begin{array}{c}\text { C30/37 } \\
\text { FL 2.5/2.0 }\end{array}$ \\
\cline { 3 - 4 } & & $\begin{array}{c}\text { FIB MC } \\
2010\end{array}$ & B3 model & $\begin{array}{c}\text { B3 model } \\
\text { mod. }\end{array}$ & $\begin{array}{c}\text { B3 model } \\
\text { mod. }\end{array}$ \\
\hline \multirow{2}{*}{$\varphi\left(t, t_{0}\right)$} & 1.869 & 1.544 & 1.463 & 1.356 \\
& 50 & 2.449 & 2.242 & 2.089 & 1.916 \\
& 100 & 2.548 & 2.384 & 2.216 & 2.030 \\
\hline
\end{tabular}

From the presented figures and tables, it can be noticed that the creep coefficient decreases with the increase of the residual flexural tensile strength, which is caused by the addition of fibres. After 100 years, the creep coefficient in the case of the concrete without fibres, C30/37, according to the improved B3 model, is 2.810, while in the case of C30/37 FL 1.5/1.5 and $\mathrm{C} 30 / 37 \mathrm{FL} 2.5 / 2.0$, with $30 \mathrm{~kg} / \mathrm{m}^{3}$ and $60 \mathrm{~kg} / \mathrm{m}^{3}$, it is 2.216 and 2.030 , according to the modified B3 model.

The creep coefficient as a function of time and coefficient $\alpha_{f}$ that represents the ratio between the residual tensile strength and concrete compressive strength $\left(\alpha_{f}=\sigma_{2} / f_{c k}\right)$, are presented in a linear scale in Fig. 9 and in a logarithmic scale in Fig. 10 for the three concrete types.

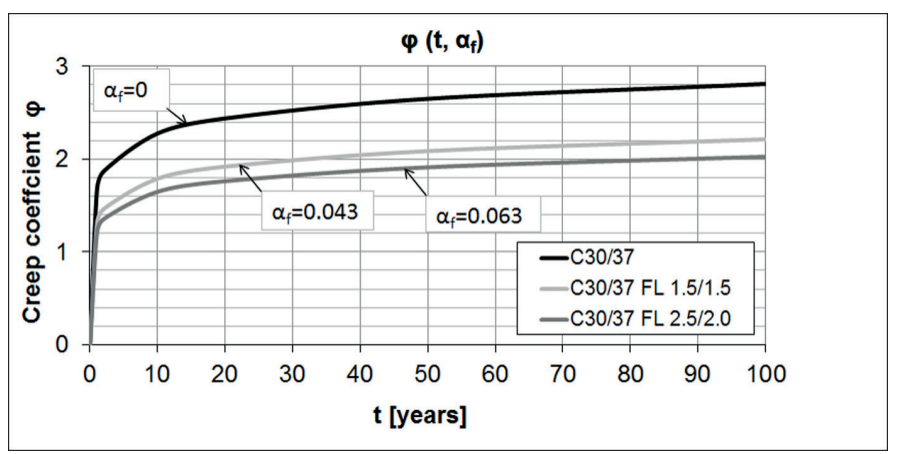

Fig. 9 Creep coefficient for the three concrete types up to the age of 100 years in linear scale

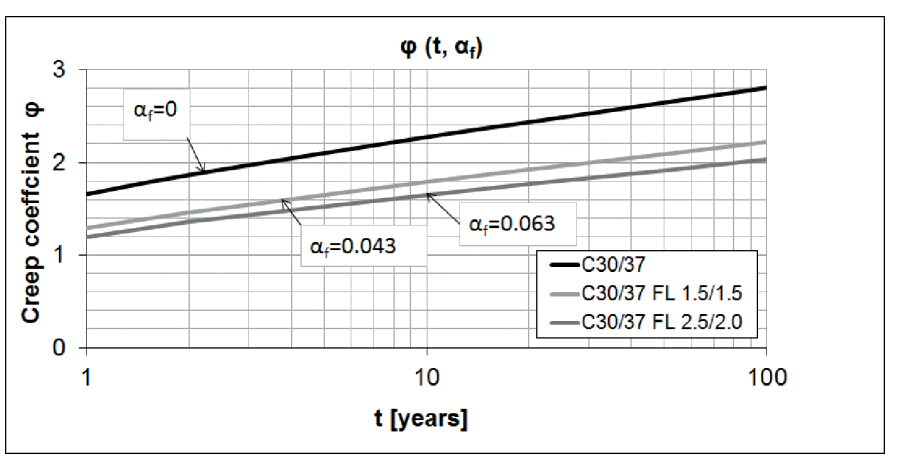

Fig. 10 Creep coefficient for the three concrete types up to the age of 100 years in logarithmic scale

\section{Conclusions}

From the experimental results and the analytical analyses of the creep strains of the steel fibre reinforced concrete specimens, the following conclusions can be drawn:

For the considered compressive stress level and according to the experimental results, at the age of concrete of 400 days, steel fibers have an influence on the creep (a decrease of up to 12\%).

According to the B3 model, based on the experimental results, at the age of 100 years, the decrease of the creep coefficient in the case of the steel fiber reinforced concrete type C30/37 FL $1.5 / 1.5$ is $11.1 \%$, while in the case of C30/37 FL $2.5 / 2.0$, it is $17.8 \%$, when compared to ordinary reinforced concrete $\mathrm{C} 30 / 37$. 
The analytical analysis of the creep strains performed by use of the B3 model and fib Model Code 2010, demonstrated an agreement with the experimental results. For concrete $\mathrm{C} 30 / 37$, an improvement of the B3 model was done on the basis of linear regression analysis. New values of coefficients $p_{1}$ and $p_{2}$ for adjustment of the creep compliance were obtained.

For the steel fibre reinforced concrete types, a modification of the flow compliance $q_{4}$ is proposed. The modification includes addition of amount of steel fibers $G_{f}$.

Further research is recommended to include different stress levels, different types of fibres (hybrid fibre reinforcement) and fibre volumes.

\section{Acknowledgement}

Recognition is accorded to the Deutscher Academischer Austausch Dienst (DAAD) and SEEFORM (South Eastern european $\mathrm{PhD}$ formation) $\mathrm{PhD}$ studies for the scholarship and the Faculty of Civil Engineering-Skopje for the financial support.

\section{References}

[1] Domski, J., Katzer, J., Zakrzewski, M., Ponikiewski. T. "Comparison of the mechanical characteristics of engineered and waste steel fiber used as reinforcement for concrete". Journal of Cleaner Production, 158, pp. 18-28. 2017. https://doi.org/10.1016/j.jclepro.2017.04.165

[2] Nakov, D., Markovski, G., Arangjelovski, T., Mark, P.: “Creeping effect of SFRC elements under specific type of long term loading”. In: Creep behaviour in Cracked Sections of fibre reinforced Concrete. RILEM Bookseries, vol. 14, Springer, Dorrdrecht. pp. 211-222. 2016. https://doi. org/10.1007/978-94-024-1001-3_17
[3] Heek, P., Ahrens, M. A., Mark, P. "Incremental-iterative model for time-variant analysis of SFRC subjected to flexural fatigue". Materials \& Structures, 50(1), artice number: 62. 2017. https://doi.org/10.1617/s11527016-0928-Z

[4] Report on Fiber Reinforced Concrete. Reported by ACI Committee 544. 1996. Reapproved 2002.

[5] Balaguru, P., Ramakrishnan, V. "Properties of Fiber Reinforced Concrete: Workability, Behaviour under Long-Term Loading and Air-Void Characteristics". ACI Materials Journal, 85(3), pp. 189-196. 1988.

[6] Bentur A., Mindess S. Fibre Reinforced Cementitious Composites. Second Edition, Taylor and Francis. 2007.

[7] Tan, K. H., Saha M.K. "Ten-year Study on Steel Fiber-Reinforced Concrete Beams under Sustained Loads". ACI Structural Journal, 103(3), pp. 472-480. 2005.

[8] Tan. K. H., Paramasivam, P., Tan K. C. "Instantaneous and Long-term Deflections of Steel Fiber-Reinforced Concrete Beams". ACI Structural Journal, 91(4), pp. 384-393. 1994.

[9] Mangat, P. S., Azari, M. M. "A Theory for the Creep of Steel Fibre Reinforced Cement Matrices under Compression”. Journal of Materials Science, 20(3), pp. 1119-1133. 1985. https://doi.org/10.1007/BF00585757

[10] Fib Model Code 2010. Fib Bulletin 65, Final Draft. 2012. http://www. fib-international.org/fib_bulletin_65_contents.pdf

[11] Gilbert, R. I., Ranzi, G. "Time-Dependent Behaviour of Concrete Structures". Spon Press, Taylor and Francis Group. 2011.

[12] Bazant, Z. P., Baweja, S. Creep and Shrinkage Prediction Model for Analysis and Design of Concrete Structures: Model B3. In: The Adam Neville Symposium: Creep and Shrinkage-Structural Design Effects, SP194, American Concrete Institute, Farmington Hills, Michigan, USA, Editor: Akthem Al-Manaseer. 2000. http://www.civil.northwestern.edu/ people/bazant/PDFs/Papers/S39.pdf 